\title{
Analysis of conventionally reinforced coupling beams using non-linear strut-and-tie model
}

\begin{abstract}
The non-linear strut-and-tie model (STM) can be used to analyse and predict the behaviour of reinforced concrete in disturbed regions. In this paper, a non-linear STM has been used to model the deformation capacity of conventionally reinforced intermediate-length coupling beams under cyclic and monotonic loads. The non-linear STM developed includes the contribution of concrete strength towards shear deformation and longitudinal bar slip through zero-length elements. The failure modes considered for the analysis were the crushing of the diagonal strut and diagonal tension (shear) failure of the beam. The model has been verified using various results of experimental works by researchers. It is found that the model could predict the behaviour and failure mode of the coupling beams rather accurately.
\end{abstract}

Keyword: Beams \& girders/buildings; Structures \& design/concrete structures 